\title{
Socio-demographic and lifestyle correlates of takeaway food consumption in UK adults
}

\author{
H.G. Janssen, I.G. Davies, L. Richardson and L. Stevenson \\ School of Sport Studies, Leisure and Nutrition, Liverpool John Moores University, Barkhill Road, Liverpool, L17 6BD.
}

Low-quality and nutrient-poor takeaway, take-out and fast foods have increased in popularity over the past 40 years and have been implicated as contributors to obesity and non-communicable disease ${ }^{(1)}$. There has been much debate regarding the determinants of takeaway food consumption, however, it is evident that the cause is multi-faceted with societal, environmental, socioeconomic, demographic, financial and behavioural factors being associated ${ }^{(2)}$. Thus, the aim of the present study was to investigate the relationship between takeaway food consumption and several socio-demographic and lifestyle variables simultaneously.

A cross-sectional observational study of 1724 adults (aged 18-64 years) was conducted from August 2016 - October 2017 in Merseyside, UK. Consumption of 212 habitual and takeaway foods was measured using a food frequency questionnaire and sociodemographic (including age, education level, ethnicity etc.) and lifestyle factors (physical activity, cigarette smoking and alcohol consumption etc.) were self-reported. All data were analysed using descriptive statistics; data was non-normal therefore, the relationship between takeaway food intake and socio-demographic and lifestyle factors was examined using Spearman's rho.

The majority (46\%) of self-reported consumers consumed takeaway food 1-3 times per month. Nonetheless, over one third ( $37 \%$ ) consumed takeaway food at least once per week (10\% reporting consumption 2-4 times per week and $1 \%$ consuming takeaway food 5 times per week or more). Having more children in the household, a physically active occupation, participating in moderate and vigorous physical activity, frequent smoking, increased alcohol consumption, poorer health status, and increased BMI were positively correlated with takeaway food consumption $(\mathrm{P}<0.005)$ (Table 1). Increased age and a higher education level were negatively correlated with takeaway food consumption $(<0.0005)$ (Table 1$)$.

Table 1. Spearman's rho correlations for takeaway food consumption and socio-demographic/lifestyle factors

\begin{tabular}{|c|c|c|c|}
\hline Socio-demographic/ lifestyle factors & Correlation coefficient $(\mathrm{R})$ & Sig. (2-tailed) & $\mathrm{n}$ \\
\hline Age Group & -0.27 & $0 \cdot 000$ & 1724 \\
\hline Adults in household & $0 \cdot 06$ & $0 \cdot 010$ & 1724 \\
\hline Children in household & 0.09 & $0 \cdot 000$ & 1724 \\
\hline Education level & $-0 \cdot 16$ & $0 \cdot 000$ & 1724 \\
\hline Health Status (Very good to Very poor) & $0 \cdot 24$ & $0 \cdot 000$ & 1724 \\
\hline Smoking frequency & $0 \cdot 11$ & $0 \cdot 000$ & 1724 \\
\hline Alcohol (drinks/ week) & 0.07 & $0 \cdot 005$ & 1720 \\
\hline Body Mass Index & $0 \cdot 08$ & 0.001 & 1693 \\
\hline Daily occupational activity & 0.09 & $0 \cdot 000$ & 1724 \\
\hline Low physical activity (min/ day) & 0.03 & $0 \cdot 208$ & 1724 \\
\hline Moderate and vigorous physical activity (min/ day) & 0.09 & $0 \cdot 000$ & 1724 \\
\hline
\end{tabular}

To conclude, the socio-demographic and lifestyle factors as shown above correlate to varying degrees with takeaway food consumption which agrees with previous research ${ }^{(3,4)}$. These findings could help inform policy and interventions to target the impacts of takeaway food on obesity and related non-communicable disease, by better understanding how takeaway food consumption links to other factors in adult lives.

1. Kant AK, Whitley MI \& Graubard BI. (2015) Int J Obes 39, 820-827.

2. Janssen HG, Davies IG, Richardson LD et al. (2017) Nutr Res Rev 2017, 1-19.

3. Lachat C, Nago E, Verstraeten R et al. (2012) Obes Rev 13, 329-346.

4. Adams J, Goffe L, Brown T et al. (2015) Int J Behav Nutr Phys Act 12, 51. 